\title{
Visualisasi Data dan Prediksi Perkembangan Impor Barang di Indonesia Tahun 2010 - 2014
}

\author{
Billy Riadi ${ }^{1}$, Johan Setiawan ${ }^{2}$ \\ Sistem Informasi, Fakultas Teknik dan Informatika, Universitas Multimedia Nusantara, Tangerang, Indonesia \\ billyriadi@gmail.com \\ johan@umn.ac.id
}

Diterima 14 Desember 2018

Disetujui 31 Desember 2018

\begin{abstract}
Import is one of the trade process conducted between two countries, the import proces (Gaffar, 2013)s is done by a country to meet the needs of the country that is not meet by the ability of the country. Indonesia also imports many items such as fuel or rice. Therefore, to reduce the level of imports, we need to know which sector has the most import rate and whether the level of imports in that sector is increasing or not, so Indonesia can save the country's foreign exchange reserves. Import data Indonesia displayed in the form of visualization of data created using the method of Visual Data Mining (VDM) and using Power BI as a tools. Indonesian Import Prediction is done to know the growth of Indonesia import rate by using Linear Regression method and using SPSS tools. In a study of the growth of import levels in Indonesia, Indonesia has an import rate that increased between $8-20 \%$, but in some periods experienced an increase and decrease caused by other factors such as consumption expenditure, currency exchange rates and state revenues.
\end{abstract}

Index Terms - IBM SPSS, Impor, Linear Regression, Power BI, Visualization

\section{PENDAHULUAN}

Impor merupakan kebalikan dari ekspor. Impor barang merupakan sebuah proses transportasi barang atau komoditas dari suatu negara ke negara lainnya secara legal, umumnya dalam proses perdagangan, seperti dituangkan dalam UU no 10 tahun 1995 [1]. Proses impor sendiri dilakukan oleh pemerintah untuk memenuhi kebutuhan Negara yang tidak bisa terpenuhi oleh penggunaan sumber daya dalam Negara tersebut. Sehingga dengan kata lain, impor sendiri adalah suatu proses perdagangan baik barang maupun jasa dari Negara lain ke dalam Negara sendiri untuk memenuhi kebutuhan negara [10].

Untuk mengetahui tingkat pertumbuhan impor tersebut maka dari itu penelitian ini dibuat agar dapat mengetahui sektor mana saja yang menjadi penyumbang impor terbesar, sehingga dapat membantu pemerintah untuk meningkatkan produksi di sektor tersebut agar mengurangi tingkat impor yang mengakibatkan penghematan devisa negara dan juga meningkatkan kesejahteraan masyarakat karena terbukanya lapangan perkerjaan. Data tentang perkembangan ini akan disajikan dengan metode Visualisasi Data.
Visualisasi data adalah metode menggunakan komputer untuk mentransformasikan simbol menjadi geometrik dan memungkinkan peneliti dalam hal mengamati simulasi komputasi yang dapat memperkaya proses penemuan ilmiah sehingga dapat mengembangkan pemahaman yang lebih dalam dan tak terduga[2]. Dengan adanya proses visualisasi terhadap big data atau raw data memungkinkan orang - orang agar dapat dengan mudah membaca dan memahami informasi yang ada dalam data tersebut karena data yang terdiri dari baris dan kolom dapat disajikan dalam sebuah Dashboard yang berisi informasi visual dalam bentuk grafik, diagram, atau Chart [3].

Berdasarkan rumusan masalah bagaimana mempermudah cara membaca suatu data tingkat impor yang masih mentah, dan melihat perkembangan tingkat impor kedepannya untuk pengambilan keputusan, maka penelitian ini dibuat untuk menjawab rumusan masalah tersebut.

\section{TINJAUAN PUSTAKA}

\section{A. Impor}

Dalam undang-undang negara Indonesia, Impor sendiri memiliki arti memasukan barang ke daerah pabean. Pabean sendiri dalam Kamus Besar Bahasa Indonesia (KBBI) memiliki arti instansi (jawatan, kantor) yang mengawasi, memungut, dan mengurus bea masuk (impor) dan bea keluar (ekspor), baik melalui darat, laut, maupun melalui udara[4]. Jadi dapat disimpulkan bahwa Impor adalah memasukan barang melalui jual beli antar dua negara dengan aturan yang berlaku di daerah pabean tersebut.

\section{B. Visualisasi Data}

Visualisasi adalah metode penggunakan komputer untuk mentransformasikan simbol menjadi geometrik dan memungkinkan peneliti dalam hal mengamati simulasi komputasi yang dapat memperkaya proses penemuan ilmiah sehingga dapat mengembangkan pemahaman yang lebih dalam dan tak terduga [2].

\section{Regresi}

Analisis Regresi merupakan metode sederhana untuk melakukan investigasi tentang hubungan fungsional di antara beberapa variabel. Hubungan 
antara beberapa variabel tersebut diwujudkan dalam suatu model matematis. Model Regresi, variabel sendiri dibedakan menjadi 2 (dua) bagian, yaitu variabel respons (response) atau biasa disebut juga variabel bergantung (dependent variable) serta variabel explonary atau biasa juga disebut variabel penduga (predictor variable) atau disebut juga dengan variabel bebas (independent variable)[5]. Regresi ialah salah satu perangkat dasar untuk analisis yang bisa digunakan untuk membuat model prediktif untuk berbagai jenis data [6].

\section{Visual data Mining (VDM)}

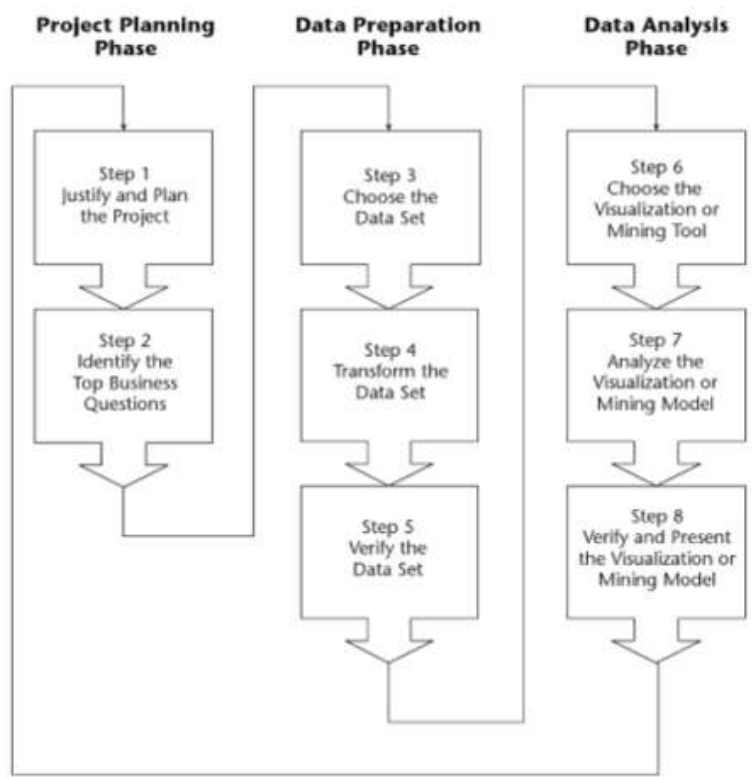

Gambar 1 Visual Data Mining [7]

Visual Data Mining[7] memiliki langkah, yaitu:

\section{Project Planing Phase}

a. Justify and Plan the Project. Pada tahap ini ditentukan bahwa project scope pada penelitian ini adalah proof of concept atau pilot pada penelitian ini. Scope pada penelitian ini adalah untuk memberikan feedback yang nantinya dapat memberikan improvement, correction, monitoring, dan dapat membantu pengambilan keputusan.

b. Identify the Top Business Question. Pada tahap ini akan dijelaskan jawaban dari pertanyaan yang ada, dimana langkah inilah yang akan menjelaskan apa yang akan dilakukan dalam penelitian ini.

\section{Data Preparation Phase}

a. Choose the Data Set. Pada tahap ini dilakukan pemilihan data yang akan digunakan dalam penelitian.

b. Transform the Data Set. Pada tahap ini, data yang telah didapatkan tadi disiapkan dengan cara melakukan cleansing seperti menghilangkan blank row atau column. Serta melakukan pengkategorian dimana data akan dipisah berdasarkan kategorinya, namun masih dalam satu file yang sama.

c. Verify the Data Set. Pada tahap ini dilakukan pengecekan ulang terhadap data yang telah disiapkan tadi, pengecekan meliputi pengecekan error pada data, blank row atau column, atau ada record dari data yang tidak sesuai dengan penelitian.

3. Data Analysis Phase

a. Choose the Visualization or Mining Tools. Pada tahap ini dilakukan pemilihan tools yang cocok terhadap penelitian ini, dimana dilakukan perbandingan - perbandingan terhadap tools yang ada.

b. Analyze the Visualization or Mining Model. Setelah memilih data visualisasi dan Data Mining tools apa yang akan digunakan kemudian langkah selanjutnya adalah bagaimana menggunakan visualisasi yang ada untuk mendapatkan informasi dari sekumpulan data tersebut dan model Data Mining yang sesuai dengan pertanyaan bisnis yang ada.

c. Verify and Present the Visualization or Mining Model. Pada tahap terakhir ini kemudian dibuat Dashboard yang akan menunjukan hasil dari analisa dan pengecekan yang telah dilakukan, dengan menggunakan tools visualization.

\section{Metodologi Penelitian}

Visual Data Mining merupakan metode yang akan dilakukan dalam penelitian tentang visualisasi ini. Metode ini dipilih untuk penelitian ini karena VDM memiliki tahapan yang lengkap dan terstruktur, tahapan VDM juga dijelaskan secara rinci sehingga mudah dipahami, sedangkan untuk Pureshare dirasa kurang cocok karena Pureshare digunakan untuk pengukuran kerja organisasi. Berikut merupakan tabel pembanding metode Pureshare, Noetix, dan VDM.

\section{A. Project Planing Phase}

Pada tahap ini ditentukan tipe project seperti apa yang akan dibuat. Pada penelitian visualisasi barang impor Indonesia ini project visualisasi akan digunakan untuk menjawab, menginvestigasi, dan menganalisis rumusan masalah yaitu bagaimana mempermudah cara membaca suatu data tingkat impor yang masih mentah, dan melihat perkembangan tingkat impor kedepannya untuk pengambilan keputusan.

Pada tahap ini akan ditentukan pertanyaan bisnis apa yang dianalisis, yaitu pada penelitian ini adalah bagaimanakah perkembangan impor barang di Indonesia selama lima tahun.

\section{B. Data Preparation Phase}

Pada tahap ini dilakukanlah pengambilan data, dimana penulis melakukan pengambilan data pada 
sebuah website yaitu data.go.id, yang berupa data impor negara Indonesia dari tahun 1999 - 2014 yang kemudian diambil hanya lima tahun saja dengan jumlah row sebanyak 366.544. Data tersebut terdiri dari tahun, bulan, kode_hs, deskripsi_hs, nilai, dan berat.

Pada tahap ini, data yang telah didapatkan tadi disiapkan dengan cara melakukan cleansing pada kolom nilai dan berat seperti menghilangkan blank value dan memilih data yang dibutuhkan yaitu tahun 2010 sampai 2014 dan melakukan pengkategorian dimana data akan dipisah berdasarkan kategorinya yaitu berdasarkan harmonized system.

Pada tahap ini dilakukan pengecekan ulang terhadap data yang telah disiapkan tadi, pengecekan meliputi pengecekan error pada data, blank row atau column, atau ada record dari data yang tidak sesuai dengan penelitian.

\section{Data Analysis Phase}

Pada tahap ini dilakukan pemilihan tools yang cocok terhadap penelitian ini, setelah dilakukan perbandingan antara tiga tools yaitu Power BI, Rapid Miner, dan Tableu, maka Power BI yang dipilih setelah melakukan berbagai pertimbangan.

Setelah memilih data visualisasi dan Data Mining tools apa yang akan digunakan kemudian langkah selanjutnya adalah menganalisa apa saja yang akan ditampilkan dalam Dashboard visualisasi impor. Data yang akan ditampilkan pada tahapan ini adalah perkembangan nilai dan berat impor dan jumlah nilai dan berat impor perbulan setiap tahunnya.

Pada tahap terakhir ini kemudian dibuat Dashboard yang akan menampilkan hasil dari analisa dan pengecekan yang telah dilakukan, dengan menggunakan Power BI. Dashboard akan menampilkan perkembangan dan jumlah impor Indonesia perbulannya yang akan ditampilkan dalam lima sheet yang mewakili setiap tahunnya..

\section{ANALISIS DAN PEMBAHASAN}

\section{A. Project Planing Phase}

Pada tahap ini dilakukan penentuan scope pada penelitian visualisasi dan prediksi perkembangan impor Indonesia tahun 2010-2014. Secara keseluruhan scope dari penelitian ini adalah untuk menentukan apakah visualisasi dan prediksi ini dapat membantu untuk melakukan pengambilan keputusan untuk perkembangan impor di Indonesia kedepannya.

Tahap ini merupakan tahap pendahuluan di dalam penelitian. Pada tahapan ini dijelaskan jawaban dari pertanyaan-pertanyaan yang ada pada pendahuluan dan dijelaskan langkah apa yang akan dilakukan dalam penelitian untuk menjawab pertanyaan-pertanyaan tersebut.

\section{B. Data Preparation Phase}

Pada langkah ini mengharuskan untuk melakukan pemilihan sumber data yang berhubungan dan membantu penelitian, yang kemudian akan dilakukan analisa, Data Mining, dan prediksi melalui data tersebut. Data yang diambil pada untuk penelitian ini tersedia dalam website data.go.id. Data dapat dilihat pada gambar 2 .

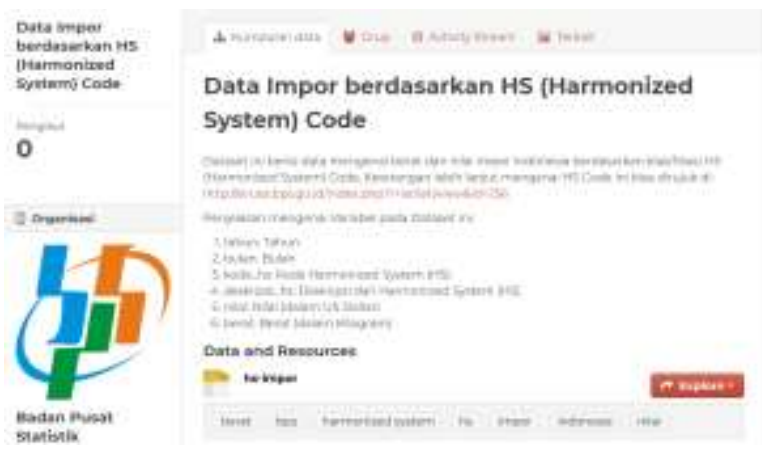

Gambar 2 Gambar Data Impor Barang [8]

Data yang didapatkan dari website data tersebut merupakan data impor barang Indonesia dari tahun 1999-2014 sesuai dengan Harmonized System (HS). Harmonized System adalah sistem klasifikasi dan pengkodean suatu komoditas berdasarkan bahan mentah, jenis produk, kualitas barang[8]. Data Impor Indonesia ini meliputi tahun impor, bulan impor, kode HS, deskripsi, nilai, dan berat.

Tahapan pertama yang akan dilakukan adalah memilih data tahun 2010 - 2014 dan menghilangkan kolom yang memiliki nilai null di dalam excel dengan menggunakan fungsi filter pada excel seperti pada gambar 3 .

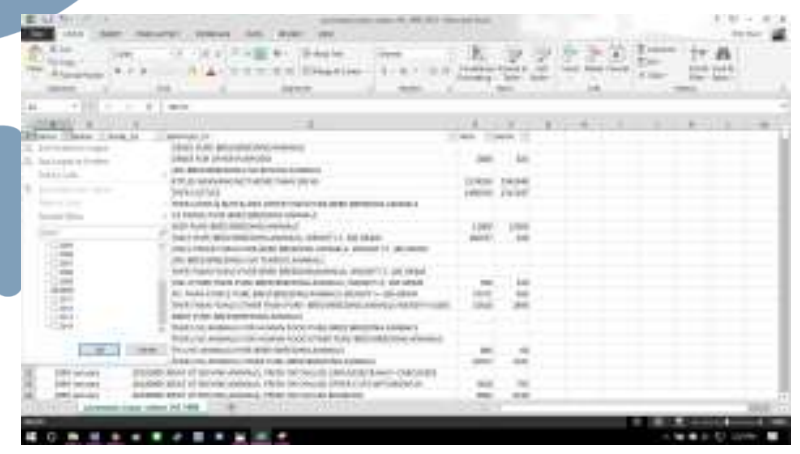

Gambar 3 Proses Filtering melalui Excel

Setelah data telah bersih kemudian dilakukan pengklasifikasian berdasarkan harmonized system yang mengklasifikasikan barang impor sesuai dengan bahan mentahnya, dimana pada gambar 4 merupakan daftar klasifikasi berdasarkan harmonized system. 
01-05 Animal \& Animal Products

06-15 Vegetable Products

16-24 Foodstuffs

25-27 Mineral Products

28-38 Chemicals \& Allied Industries

39-40 Plastics / Rubbers

41-43 Raw Hides, Skins, Leather, \& Furs

44-49 Wood \& Wood Products

50-63 Textiles

64-67 Footwear / Headgear

68-71 Stone / Glass

72-83 Metals

84-85 Machinery / Electrical

86-89 Transportation

90-97 Miscellaneous

\section{Gambar 4 Harmonized System}

Data yang telah bersih dan sudah diklasifikasi kemudian akan dipakai untuk melakukan prediksi menggunakan linear regression. Sebagai contoh data yang digunakan pada prediksi ini merupakan data dari klasifikasi Animal \& Animal Product.

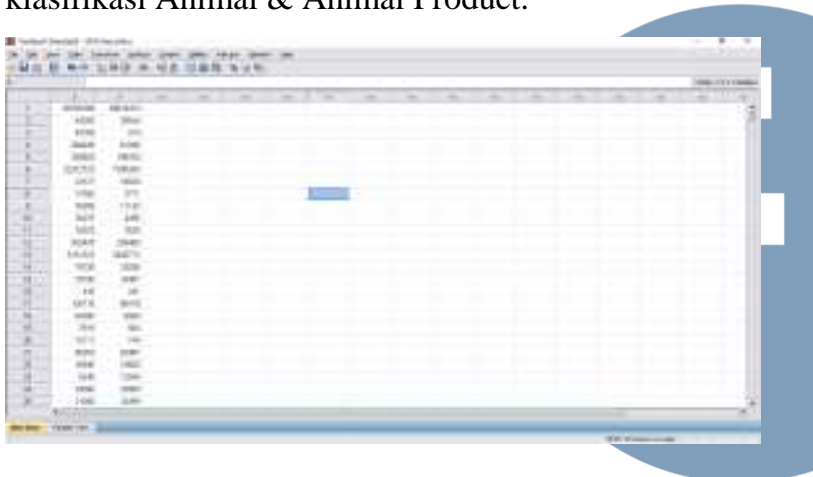

Gambar 5 Data Animal \& Animal Product

Gambar 5 merupakan data animal \& animal product yang telah di import ke dalam IBM SPSS dan akan digunakan dalam memprediksi nilai impor animal \& animal product untuk tahun-tahun berikutnya.

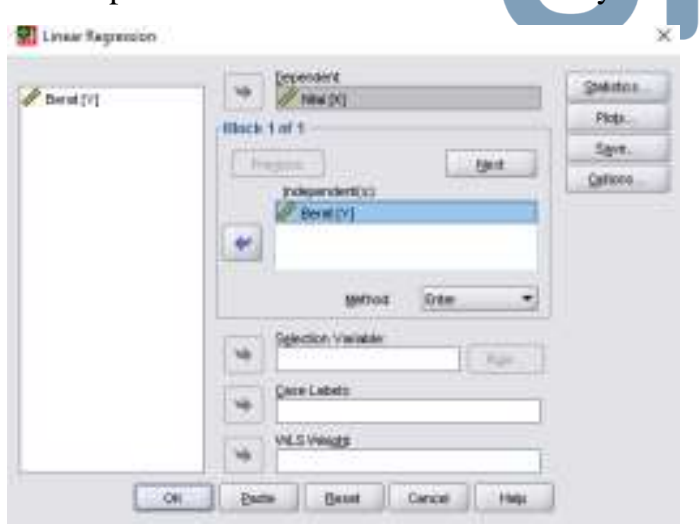

Gambar 6 Pemilihan Variabel

Data nilai impor merupakan data yang akan diprediksi sehingga dipilih sebagai variabel dependent dan data berat sebagai variabel independent karena data berat yang mempengaruhi nilai data nilai impor.

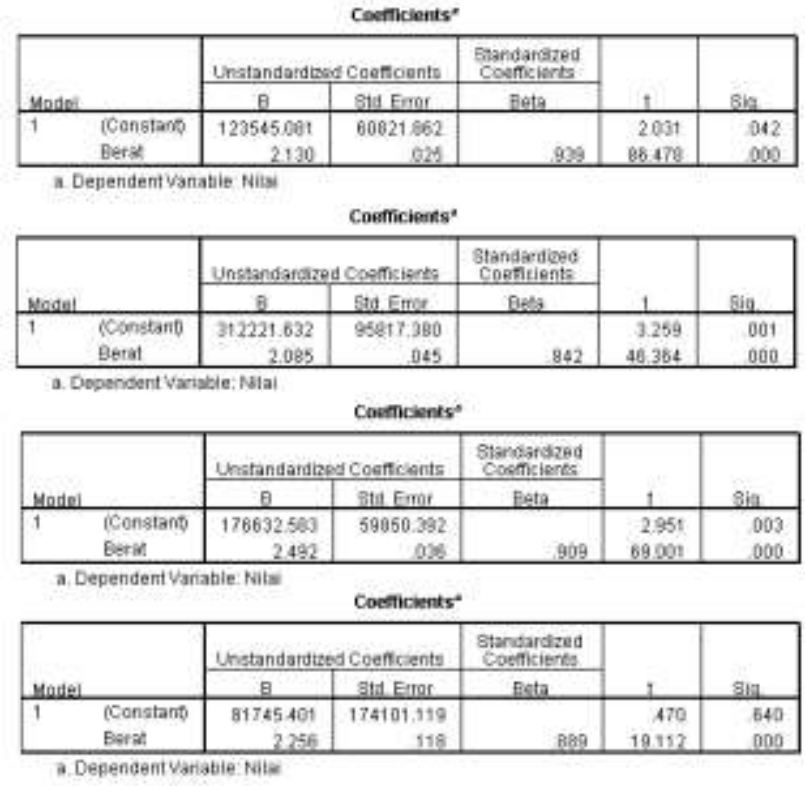

Gambar 7 Nilai Koefisien dan Konstanta

Setelah data diolah dan dianalisis dengan IBM SPSS maka akan muncul hasil seperti pada gambar 7 yang menghasilkan nilai koefisien dan konstanta yang dapat dilihat pada tabel 1. Apabila nilai sigma yang dilambangkan dengan Sig. Lebih dari 0.05 maka data dapat digunakan.

Tabel 1 Nilai A dan B

\begin{tabular}{|c|c|c|}
\hline Tahun & A & B \\
\hline 2010 & 123545.081 & 2.130 \\
\hline 2011 & 312221.632 & 2.085 \\
\hline 2012 & 176632.583 & 2.492 \\
\hline 2013 & 81745.401 & 2.256 \\
\hline
\end{tabular}

Setelah didapatkan nilai A dan B maka dapat dilakukan perhitungan prediksi sesuai linear regression dengan rumus yang dilakukan dengan software IBM SPSS.

$$
Y=a+b X
$$

Keterangan

$\mathrm{Y}=$ Variabel Response atau Variabel Akibat (Dependent)

$\mathrm{X}=$ Variabel Predictor atau Variabel Faktor Penyebab (Independent)

$\mathrm{a}=$ konstanta

$\mathrm{b}=$ koefisien Regresi (kemiringan) besaran Response yang ditimbulkan oleh Predictor.

Berdasarkan perhitungan dengan menggunakan metode tersebut maka didapatkan hasil yang akan ditunjukkan pada tabel 1.2. 
ISSN 2085-4579

Tabel 2 Nilai Prediksi

\begin{tabular}{|c|c|c|c|}
\hline Tahun & Prediksi & Hasil Aktualnya & Akurasi \\
\hline 2011 & 1.576 .513 .333 & 1.566 .875 .725 & $99.3 \%$ \\
\hline 2012 & 1.566 .911 .335 & 1.417 .592 .172 & $90.5 \%$ \\
\hline 2013 & 1.425 .017 .858 & 1.533 .977 .890 & $92.9 \%$ \\
\hline 2014 & 103.891 .317 & 164.338 .557 & $63.2 \%$ \\
\hline
\end{tabular}

Setelah data di transformasikan dan di cleansing untuk kemudian di visualisasikan, pada tahapan ini tahapan-tahapan yang sudah dilakukan, dicek kembali apakah masih memiliki data yang error ataukah masih ada field yang tidak diperlukan namun masih tersimpan di dalam data.

\section{Data Analysis Phase}

Untuk Data Mining Tools digunakan Power BI untuk visualisasi. Power BI dipilih karena memiliki kelebihan - kelebihan yang dapat dilihat di tabel 1.3, dan juga karena memiliki wawasan yang lebih besar mengenai Power BI.

Tabel 3 Perbandingan Feature Tools.

\begin{tabular}{|c|c|c|c|}
\hline Tools & $\begin{array}{c}\text { Power } \\
\text { BI }\end{array}$ & $\begin{array}{l}\text { Rapid } \\
\text { Miner }\end{array}$ & Tableau \\
\hline \multicolumn{4}{|l|}{ Platform Supported } \\
\hline Web Based & $v$ & $v$ & $v$ \\
\hline Iphone App & $v$ & & $v$ \\
\hline Android App & $v$ & & $v$ \\
\hline Windows Phone App & $v$ & & \\
\hline \multicolumn{4}{|l|}{ Features } \\
\hline Business Intelligence & $v$ & $v$ & $v$ \\
\hline Data Visualization & $v$ & $v$ & $v$ \\
\hline Dashboard Creation & $v$ & $v$ & $v$ \\
\hline
\end{tabular}

Setelah memilih visualisasi dan Mining tools yang akan digunakan dalam penelitian ini, kemudian pada tahap ini dianalisa apakah model dari visualisasi tersebut cocok dipakai dalam penelitian ini, selanjutnya bagaimana menggunakan visualisasi tersebut untuk mendapatkan informasi dari sekumpulan data.

Tahapan terakhir adalah dengan memvisualisasikan data hasil pengolahan dan prediksi, karena itu dibuatlah suatu dashboard yang akan menampilkan seluruh informasi agar dapat dipahami dengan mudah.

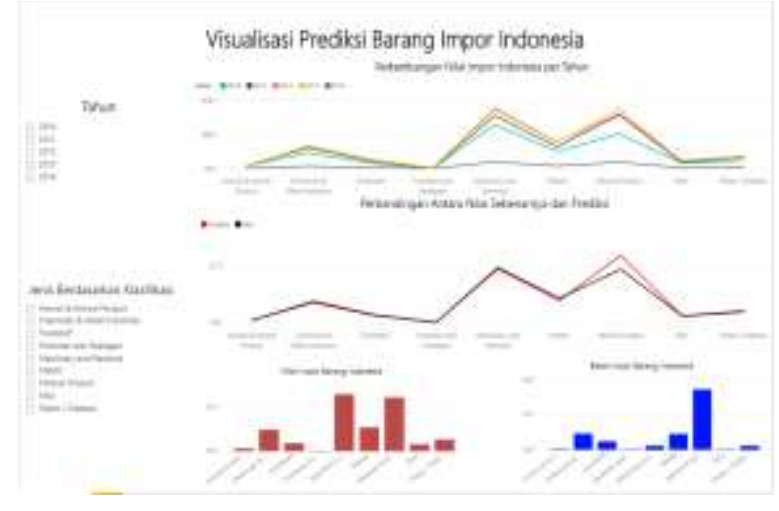

Gambar 8 Dashboard Visualisasi Prediksi

Gambar 8 yaitu dashboard hasil visualisasi berisikan dua buah slicer yang dipakai sebagai filter dalam proses pembacaan dashboard. Slicer pertama berisikan tahun impor dan slicer kedua berisikan klasifikasi sesuai dengan harmonized system. Dalam dashboard juga terdiri dari dua buah line chart, dimana line chart pertama berisikan tentang perkembangan impor barang di Indonesia dan line chart kedua berisikan tentang perbandingan antara nilai aktual dari impor barang dan dari hasil prediksi yang telah dilakukan. Chart terakhir merupakan bar chart yang menunjukkan nilai impor barang di Indonesia dan berat barang yang diimpor oleh Indonesia.

\section{SIMPULAN}

Visualisasi yang telah dibuat, menampilkan bagaimanakah perkembangan impor di Indonesia. Impor Barang di Indonesia didominasi oleh produkproduk mineral seperti bahan tambang, hal ini berarti bahwa Indonesia masih sangat bergantung terhadap negara lain untuk memenuhi kebutuhan barang tambang, kemudian disusul oleh impor barang bahan kimia yang menempati produk paling banyak diimpor kedua, sedangkan untuk impor barang paling sedikit ada pada produk raw hides, skins, dan leathers yang berarti pada sektor ini Indonesia masih bisa memenuhi kebutuhan pada sektor ini. Nilai Impor Indonesia sendiri mencapai puncaknya pada tahun 2012 dimana tahun ini memiliki nilai impor tertinggi, dan pada tahun 2014 memiliki tingkat impor terendah. Perkembangan impor barang di Indonesia dari tahun ke tahun memiliki angka yang cenderung meningkat sebesar $8-20 \%$, ini dapat dilihat dari hasil visualisasi tentang perkembangan nilai impor di Indonesia. Hasil penelitian menunjukan bahwa dari tahun ke tahun Indonesia semakin banyak membutuhkan barangbarang impor, misalnya barang impor berdasarkan bahan tambang, yang berarti Indonesia masih memiliki kekurangan dalam mengolah hasil tambang, dalam klasifikasi ini saja dapat dilihat apabila Indonesia dapat mengolah hasil olahan tambang maka dapat mengurangi impor yang berdampak pada penghematan cadangan devisa negara.

Prediksi dengan menggunakan metode linear regression memiliki tingkat akurasi yang tinggi untuk bentuk data yang digunakan dalam prediksi impor 
barang Indonesia, dengan rata - rata nilai akurasi mencapai 80-90\%, namun di beberapa kategori terkadang tingkat akurasi menurun ke angka 60-70\%, ini dikarenakan faktor dependent yang digunakan hanya satu, sedangkan banyak hal yang berpengaruh terhadap impor, misalnya pengeluaran konsumsi, tingkat kurs mata uang, dan pendapatan negara. Namun secara keseluruhan tingkat akurasi dengan metode linear regression cukup tinggi [9].

\section{UCAPAN TERIMA KASIH}

Ucapan rasa syukur dan terima kasih kepada semua pihak yang telah membantu, terutama Bapak Johan Setiawan yang telah membimbing dan mendukung penyelesaian penelitian ini dari awal hingga akhir penulisan.

\section{DAFTAR PUSTAKA}

Untuk penamaan daftar pustaka, gunakan tanda kurung siku, seperti [1], secara berurutan dari awal rujukan dilakukan. Untuk merujuknya dalam kalimat, cukup gunakan [2], bukan "Rujukan [3]", kecuali di awal sebuah kalimat, seperti "Rujukan [3] menggambarkan ...."

Penomoran catatan kaki dilakukan secara terpisah dengan superscripts. Letakkan catatan kaki tersebut di bawah kolom dimana catatan kaki tersebut dirujuk. Jangan letakkan catatan kaki di dalam daftar pustaka.

Kecuali terdapat enam atau lebih penulis, jabarkan nama penulis tersebut satu-satu, jangan gunakan "dkk". Artikel yang belum diterbitkan, meskipun sudah dikirim untuk diterbitkan, harus ditulis "belum terbit"
[4]. Artikel yang sudah dikonfirmasi untuk diterbitkan, namun belum terbit, harus ditulis "proses cetak" [5]. Gunakan cara penulisan kalimat (Sentence case) untuk penulisan judul artikel.

Untuk artikel yang diterbitkan dalam jurnal terjemahan, tuliskan terlebih dahulu rujukan hasil terjemahannya, diikuti dengan jurnal aslinya [6].

[1] Negara, S. (1995). Undang-Undang Republik Indonesia. Retrieved from Sekretariat Negara: https://ktln.setneg.go.id/pdf/Fasilitas/UU_10_1995.pdf

[2] Li, X., Feng, Y., \& Mustoe, G. (2017). Proceedings of the 7th International Conference on Discrete Element Methods. Singapore: Springer Nature.

[3] Laudon, K. (2010). Managemen Information System. Harlow: Pearson Education Limited.

[4] Hukumonline.com. (2014). Peraturan Perdagangan. Retrieved from Hukum Online: http://www.hukumonline.com/pusatdata/detail/lt5332a3e55eb 82/nprt/lt51a8623f2fb9d/undang-undang-nomor-7-tahun2014

[5] Nawari. (2010). Analisis Regresi dengan Microsoft Excel dan SPSS 17. Jakarta: PT. Elex Media Komputindo.

[6] Olson, D., \& Shi, Y. (2008). Introduction to Business Data Mining. Pensylvania: McGraw Hill.

[7] Soukup, T., \& Davidson, I. (2002). Visual Data Mining : Techniques and Tools for Data Visualization and Mining. New Jersey: John Wiley \& Sons.

[8] Badan Pusat Statistik. (2014). Harmonized System. Retrieved from Badan Pusat Statistik: https://sirusa.bps.go.id/index.php?r=istilah/view\&id=256

[9] Imam, A. (2013). Faktor - faktor yang Mempengaruhi Impor Barang Konsumsi di Indonesia. Jurnal Ekonomi Pembangunan

[10] Gaffar, A. (2013). Konstruksi Realitas Impor Beras oleh "Kompas Online" Analisi Wacana Kritis. MIMBAR, 187-194.

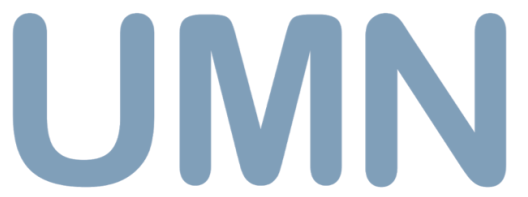

